\title{
Staying Focused: Highlighting-on-Demand as Situational Awareness Support for Groups in Multidisplay Environments
}

\author{
Olga Kulyk ${ }^{1}$, Tijs de Kler ${ }^{2}$, Wim de Leeuw ${ }^{3}$, \\ Gerrit van der Veer ${ }^{4}$, and Betsy van Dijk ${ }^{1}$ \\ 1 Human Media Interaction, University of Twente, The Netherlands \\ 2 SARA Computing and Networking Services, Amsterdam, The Netherlands \\ 3 Integrative Bioinformatics Unit, University of Amsterdam, The Netherlands \\ 4 Open University, The Netherlands
}

\begin{abstract}
User interfaces and visualisations are part of group problem solving. Technology is already a part of daily decision-making in multidisplay environments, both as communication tools and information devices. As these devices, such as large displays and visualisation tools become more accessible, there is an increasing opportunity to develop applications that enhance group decision-making abilities, rather than restrict them. This chapter presents the results of the empirical user study on the effect of the Highlighting-on-Demand concept on situational awareness and satisfaction with the group decision-making process in a real multidisplay environment. Highlighting-on-Demand interface enables a team member who is currently controlling the shared large display to draw attention of the other team members by highlighting certain visualisation. Displaying all alternatives on a shared large display fosters information sharing and the Highlighting-on-Demand interface enables group members to draw attention to certain visualisation, while keeping the other alternatives still in view.

The results suggest that when group members use the Highlightingon-Demand interface during the discussion, the satisfaction with the final group decision increases. Participants expressed willingness to use the Highlighting awareness support for visualising real data (e.g., biomedical, omics experiments) and manipulating how the data is visualised to discuss the experiment results with other team members in real project discussions.
\end{abstract}

\section{Introduction}

The complexity of communication processes in a co-located decision-making environment requires the combination of several approaches to support situational awareness. This, in turn, requires a practical method to capture and analyse the dynamics of technology-mediated interactions in context. The nature of the interfaces as well as the physical characteristics and affordances of the environment influence the way in which interactions occur [Fruchter and Cavallin, 2006]. 
Therefore our approach for data analysis includes a combination of behaviour, interaction and environment analysis.

We will assess shared situational awareness of team members when we provide supportive visualisations on a shared large display. We aim at reducing disturbing factors that are considered a distraction from the primary group decisionmaking task. We intend to establish an indication of the relations between situational awareness, team satisfaction, group processes like decision making and the perceived task performance. Video recordings from several viewpoints will enable us to analyse several simultaneously ongoing interactions. In addition to observations, post-interviews and questionnaires are carried out to obtain subjective judgments of the team members, for example, on group satisfaction, awareness and distraction from primary tasks Cadiz et al., 2002; Kulvk et al., 2007; Olaniran, 1996]. Group satisfaction will be assessed by a combined validated post-task questionnaire featuring the group process and decision making Olaniran, 1996]. We apply these questions to assess the perceived usefulness and impact of the Highlighting-on-Demand interface on the shared situational awareness of team members, on distraction from the primary task, and on team satisfaction with the group process and decision-making process.

\section{Theory Grounding}

\subsection{Situational Awareness}

Situational awareness is expected to be an important determinant of team performance [Bolstad et al., 2005; Endslev, 1995a]. SA provides the "primary basis for subsequent decision making and performance in the operation of complex, dynamic systems..." Endslev, 1995a]. At its lowest level the team member needs to perceive relevant information (in the environment, system, self, etcetera), next integrate the data in conjunction with task goals, and, at its highest level, predict future events and system states based on this understanding [Endslev, 1995a].

Situation Awareness theory primarily focuses on how visual information influences the ability of groups to formulate a common representation of the state of the task, which in turn allows them to plan and act accordingly Endslev, 1995b, 1993]. Visual information helps team members assess the current state of the task and plan future actions [Endslev, 1995b; Whittaken, 2003]. This awareness supports low-level coordination for tightly-coupled interactions.

The most commonly cited definition of SA is one suggested by Endslev [1995b] who states that situational awareness "...is the perception of elements in the environment within a volume of time and space, the comprehension of their meaning, and the projection of their status in the near future" (p. 36, more elaborated 3levels definition of SA is presented in Kulvk, 2010]). Despite the frequency of its citation, many researchers do not accept this definition of SA. For example, Wickens 1992] suggests that SA is not limited to the contents of working memory, but it is the ability to mentally access relevant information about the 
evolving circumstances of the environment. Crane 1992 provides a very different conceptualization of situational awareness by focusing on inadequate performance and suggests that SA is synonymous with expert-level performance.

In this research, we define situational awareness as: (1) detection and comprehension of the relevant perceptual cues and information from the environment; (2) understanding of the situation, based on individual previous knowledge; and (3) interpretation of these and reconfiguration of understanding and knowledge in a continuous process during the group collaboration effort. This allows awareness of changes in the environment, knowing what team members are doing and have done regarding current events in the environment, and keeping track of work progress.

Especially in multidisciplinary settings situational awareness information is affected by the abilities of individual members, their interaction with other team members, and the environment in which they collaborate [Bolstad et al, 2005]. Various factors affect individual situational awareness formation: environmental (physical location, display arrangement and size, etcetera) and group aspects (communication, use of collaboration tools, team processes, etcetera). In order to assess SA during evaluation of collaborative interfaces or awareness displays, specific factors need to be identified relevant to a particular domain. Applying an iterative user-centered design approach, we need to analyse the actual work context in order to design technology that supports team members in their primary task. Thus, this leads teams to communicate and interact in a collaborative environment with prolonged involvement and, hopefully, better results. It will also help us to find out how new technology in collaborative environments, such as large shared displays, influences daily work and team coordination Hallnass and Redstrom, 2002. This and other aspects of situational awareness theory are extensively addressed in Kulvk, 2010.

Based on the theory of situational awareness [Endslev, 1995a and on the results of our previous user study and task analysis study [Kulvk, 2010], displaying all alternatives on a shared large display should foster information sharing and the Highlighting interface should enable group members to draw the attention of the group to a certain visualisation, while still keeping the other alternatives in view. The Highlighting-on-Demand concept supports level 1 of situational awareness, perception. The detailed description of the Highlighting-on-Demand interface, as well as results of the user evaluation are presented in section 5 of this chapter.

\subsection{Social Psychology of Groups and Technology}

Research in social psychology has demonstrated that our ability to make group decisions is frequently flawed because we overly rely on social cues during a group discussion McGrath, 1984; McGrath and Hollingshead, 1993]. Conversations held by groups for the purpose of making decisions are fraught with complications. Social psychologists have demonstrated that individuals allow the presence of the other people in the group to influence their behavior to such a degree that through 
the process of exchanging opinions, the group is led to a lower quality decision, as compared to aggregating individual decisions Brav et al., 1982; Hackman, 1992; Janis, 1982; Mvers and Bishop, 1971; Whvte, 1991|.

While groups have flawed decision processes, Raven [1998] describes a wellknown experiment that aptly illustrates the difficulty in universally stating that groups hinder decision-making. The results of his experiment show that the groups that reached a unanimous decision felt more satisfied with their decision than those that did not, even if they were shown to be incorrect in their judgment. This experiment illustrates that individuals rely on the opinion of others as an indicator of the accuracy of their judgments, but this reliance can occasionally lead to an error in judgment. Yet, as a corollary to this, if a criterion of decision success is satisfaction with the outcome, then individuals' use of this decision-making strategy may be beneficial even in cases where their judgment is wrong.

With this understanding of the complexity of our limitations, what can we do to limit the harm and harness the benefits of groups? By altering its decisionmaking process, a group can avoid the above communication flaws and overreliance on others. According to DiMicco et al. 2004] and based on the related studies on the psychology of groups, there are three possible areas that should be examined to enhance decision-making processes with technology. First, determine ways to encourage vigilance in considering choice alternatives in the discussion Janis, 1982]. Second, limit the effects of group polarisation (a group's tendency to shift towards risk or caution) Brown, 1986|. And third, increase the sharing of information between individuals [Stasser and Titus, 1987].

For example, vigilance can be fostered by a system that keeps all the alternative ideas in front of the group, and makes the infrequently mentioned alternatives re-appear within the discussion. Group polarization can be limited with a reframing of decisions in terms of gains, not losses, and an interface or tool that enables a group to reframe questions from different points of view. Information sharing can be encouraged within a group by allowing the documentation and presentation of individual decisions that will later be shared with the group.

Technology is already a part of daily decision-making environments (e.g., smart meeting rooms and multidisplay environments), both as communication tools and information devices. As these devices (e.g., large displays) and tools become more accessible, there is an increasing opportunity to develop applications that enhance group communication abilities, rather than restrict them. If tools can be designed such that the satisfaction with the group decision-making process increases, then the potential for achieving more gains of group interaction increases.

\section{Objectives and Hypotheses}

Based on the results of the exploratory user study and task analysis results Kulvk, 2010], we have come up with a number of situational awareness (SA) concepts to explore various alternative solutions [Kulvk et al., 2008] in order to 
support group decision making in co-located collaborative environments, presented in Kulvk, 2010. One example is a Highlighting-on-Demand interface, which enables a team member who is currently controlling the shared display to draw the attention of the other team members by highlighting a certain visualisation, for example, using a slider on a shared display or a personal interaction device.

The goal of this experiment is to perform a controlled comparative case study in order to measure the effect of the Highlighting-on-Demand concept on: a) satisfaction with the final group decision and b) satisfaction with the group decision-making process in a multidisplay environment. We will assess satisfaction with the decision-making process of team members, providing supportive visualisations on a shared large display. We aim at reducing the distraction from the primary decision-making task, and increasing the group member's satisfaction, with the decision-making process and group communication, as well as satisfaction with the perceived task performance (individual decision versus group decision).

Based on theories on the formation of shared situational awareness Kulvk, 2010 and social psychology of groups Janis, 1982; Brown, 1986; Stasser and Titus, 1987], displaying all alternatives on a shared large display should foster information sharing and the highlighting interface should allow group members to draw attention of the group by highlighting a certain alternative, while keeping the other alternatives still in view. Therefore, by presenting all alternatives on a shared large display and enabling highlighting on a shared touch screen, it is hypothesized that satisfaction with the group decision-making process will increase. These predictions are summarized as two hypotheses:

H1 - In the condition with the Highlighting-on-Demand interface, participants' satisfaction about group process and decision-making process will be higher.

H2 - Participants' satisfaction about the final group decision, in relation to their individual decision, will be higher in the condition with the Highlightingon-Demand interface.

Next section presents the experiment design and procedure.

\section{Setting and Procedure}

Within-group design is applied in this experiment, which means that each group of participants performs a group decision-making task in both conditions: one Without $(\mathrm{N})$ and one With $(\mathrm{Y})$ the Highlighting interface. The conditions are balanced (See Table 1 below). 
Table 1. Experiment design

\begin{tabular}{l||l|ll|l}
\hline $\begin{array}{l}\text { Group } \\
\text { Session }\end{array}$ & $\begin{array}{l}\text { Condition } \\
(\mathrm{N} / \mathrm{Y})\end{array}$ & $\begin{array}{l}\text { Image } \\
(\mathrm{A} / \mathrm{B})\end{array}$ & $\begin{array}{l}\text { Set } \\
\text { Section 4.5 below) }\end{array}$ \\
\hline \hline $\mathbf{1}$ & $\mathrm{N}$ & $\mathrm{A}$ & $\begin{array}{l}\text { Part I } \\
\text { Part I \& II }\end{array}$ \\
\hline $\mathbf{2}$ & Y & B & $\begin{array}{l}\text { Part I \& II } \\
\text { Part I }\end{array}$ \\
\hline $\mathbf{3}$ & N & B & A & Part I \\
& Part I \& II \\
\hline \multirow{4}{*}{} & Y & B & A & Part I \& II \\
& Part I \\
\hline
\end{tabular}

\section{Legend, Table 1 .}

Conditions:

$\mathrm{N}(=\mathrm{NO})$ : Without Highlighting

Y (=YES): With Highlighting

Image Sets:

Set $\mathrm{A}=7$ various large paintings (landscape, portrait, abstract, fantasy etc.) Figure 11

Set $\mathrm{B}=$ a set of 7 other various large paintings - Figure 2 ,

\subsection{Target Group}

The chosen target group for this experiment is ad-hoc small groups of four to five members. Group members are scientists who might be colleagues working together at the same faculty at the university, or in the same research group (e.g. human-computer interaction or visalisation research group), with multidisciplinary backgrounds. We mixed-up group members to create balanced small groups. As a result, some of the participants knew each other well beforehand, and others have never worked in one team together.

\subsection{Group Task Scenario}

In this study we address the domain of the group decision making which involves group discussion and review of the arguments prior to making a final decision. The goal of the group task in this study was to initiate a group discussion on a topic of joint interest and motivate the team members to develop an individual and a group decision-making strategy. Since it was not feasible to find several life science teams to participate in the study, we decided to choose a general task for group decision making, not related to omics experimentation or life sciences. Taking into account that ad-hoc groups consist of group members from different disciplines, we picked a general task, which would be of interest to each participant and to the whole group at the same time. 

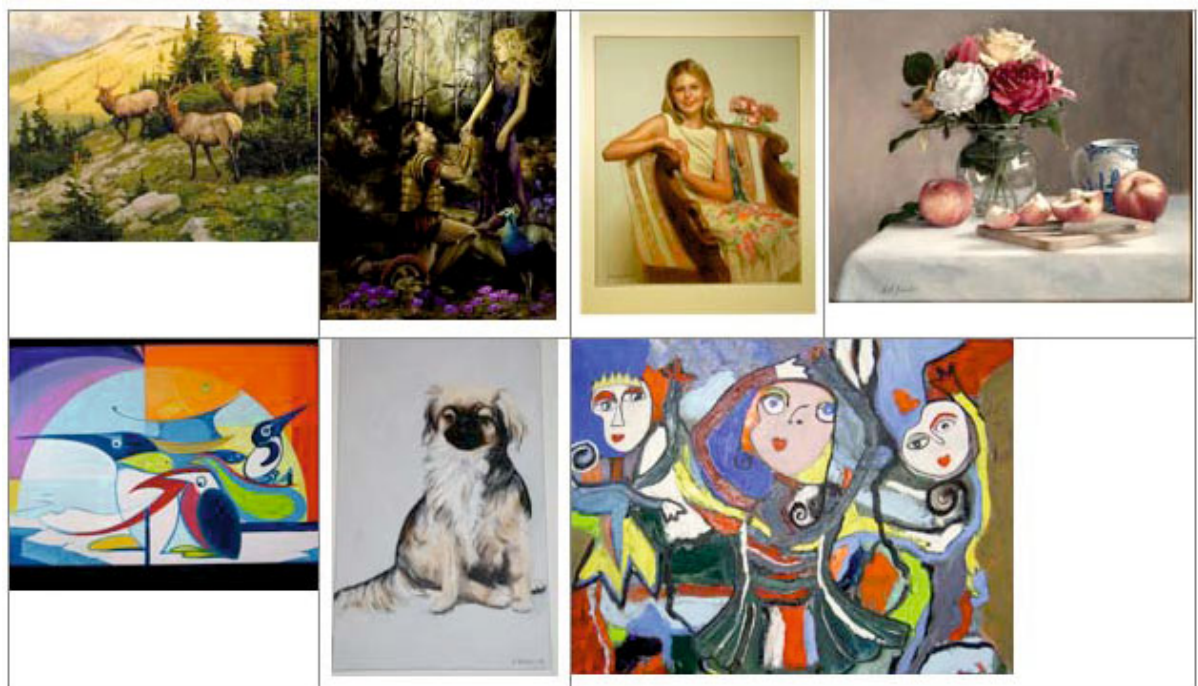

Fig. 1. Paintings: set A

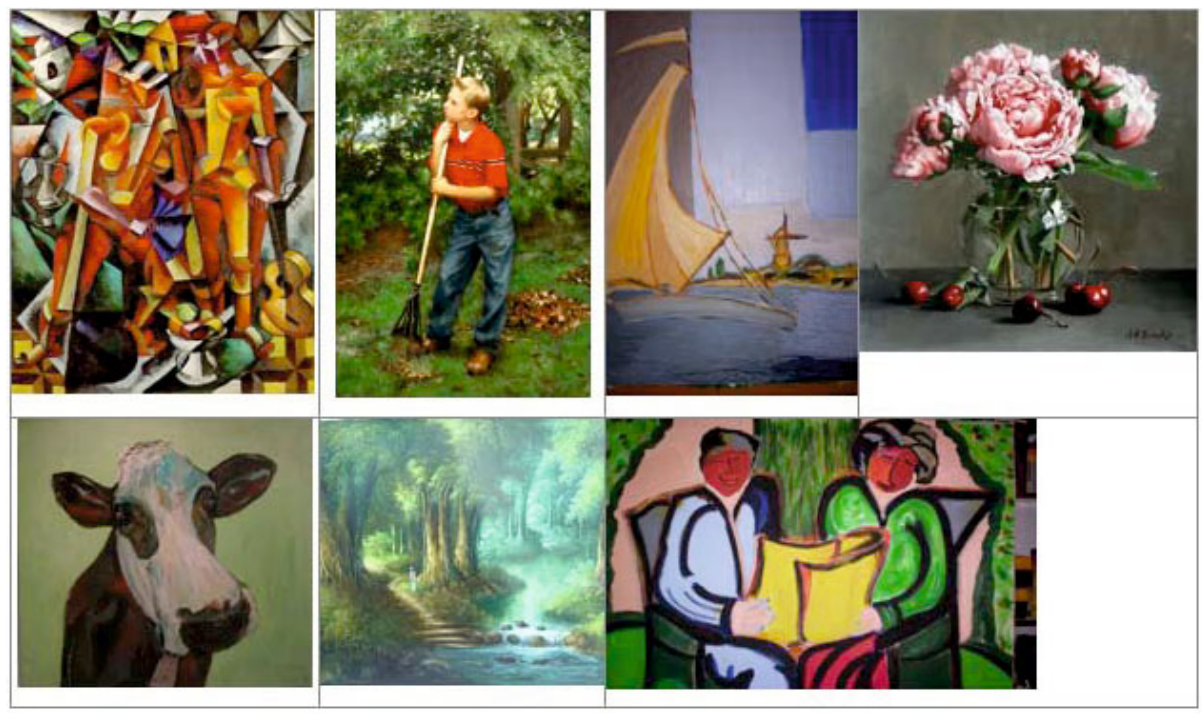

Fig. 2. Paintings: set B

A group decision-making scenario was presented as a group task, where a group had to discuss seven paintings and then pick three of them to put it in the shared coffee room. After discussing each painting with the whole team, and the pros and cons of putting it in the shared coffee room, each group member had to pick a maximum of three favourite paintings individually. After that, 


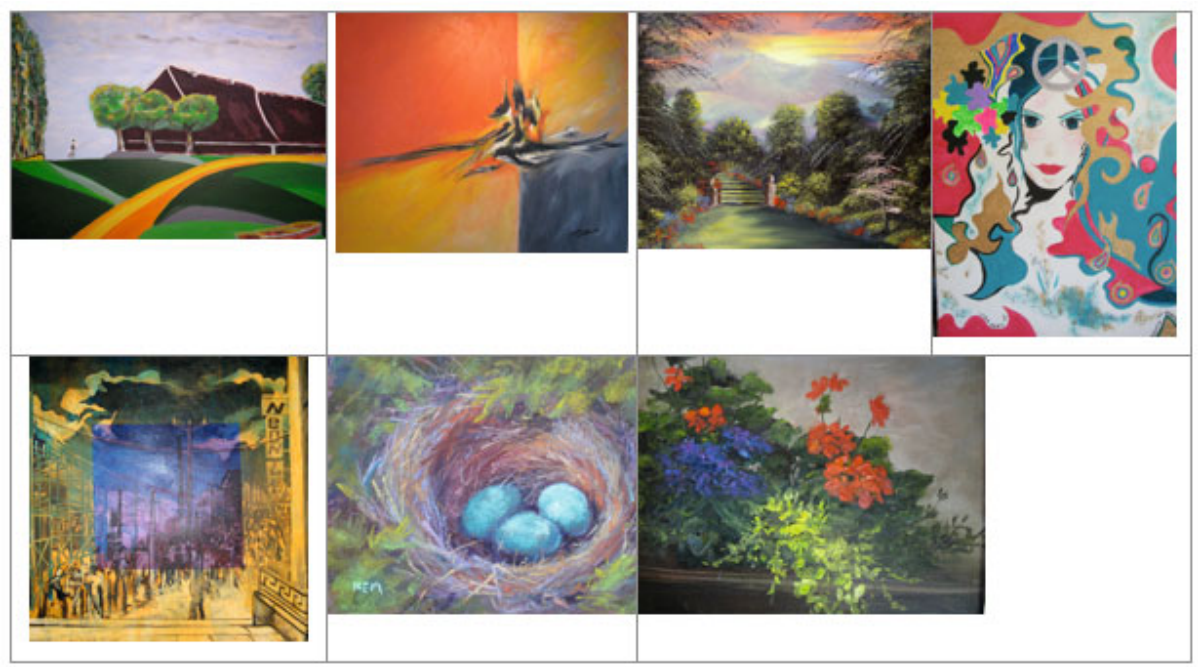

Fig. 3. Paintings: test set 0

Table 2. Session planning - group session 1 (see Table II)

\begin{tabular}{|c|c|}
\hline $\begin{array}{l}\text { Time duration } \\
\text { (Total: } 60 \text { min.) }\end{array}$ & Activity \\
\hline 7 min. & $\begin{array}{l}\text { Intro \& Example (interaction via plasma touch screen) - Image } \\
\text { Test Set } \mathbf{0} \text { (Figure } 31 \text { ) }\end{array}$ \\
\hline 10 min. & $\begin{array}{l}\text { Task }(\mathrm{N}=\text { No Highlighting, only moving) - Image Set A } \\
\text { (Figure II) }\end{array}$ \\
\hline 5 min. & Pre-Questionnaire (Part I) \\
\hline $3 \mathrm{~min}$. & $\begin{array}{l}\text { Intro \& Example (Highlighting \& resizing) - Image Test Set } \\
\text { o (Figure 31) }\end{array}$ \\
\hline 10 min. & $\begin{array}{l}\text { Task (Y = With Highlighting \& resizing) - Image Set B (Fig- } \\
\text { ure 21) }\end{array}$ \\
\hline 10 min. & Post-Questionnaire (Part I \& II) \\
\hline $5 \mathrm{~min}$. & $\begin{array}{l}\text { Illustrate extra function: Highlight one image, fade out the rest } \\
\text { automatically }\end{array}$ \\
\hline $10 \mathrm{~min}$. & Debriefing: post group interview \\
\hline
\end{tabular}

\section{Legend, Table 2]}

Set $0=$ a set of 7 different large paintings (Figure [3) used only for the introduction.

participants were asked to play a ranking game, where everybody had to share their individual choice with the rest of the group by dividing 3 points between three, two or one painting. Finally, a group had to reach a decision by picking three paintings only, either by summing up the individual scores or by agreeing on the mutual group decision. 
Each group had a limited time of ten minutes to reach a group decision. The main goal for the group was to reach a group decision that each group member would agree with. Each participant received a $€ 8$ gratuity coupon for their participation.

\section{Instructions to the group}

Your faculty at UvA has received 7 paintings as a present from students of Utrecht Art Academy. Only 3 paintings can be put in the coffee room of your research group. Your goal is to discuss these 7 paintings (presented on a large tiled display in front of you) as a group and choose 3 paintings for the coffee room of your research group. After discussing each painting (pros/cons, why you like it, why does it suit in the coffee room etc.) in a group, you will have to score them to make a group decision. Each of you will have 3 points that you can choose to either divide between 2 (e.g.: Painting $3=2$ points, Painting $5=1$ point) or 3 paintings, or you can give all 3 points to just one painting of your personal choice. You have to announce your group choice of favorite 3 paintings after 10 minutes. Please use a blank A4 page or a whiteboard (on your right) to put your personal and group scores.

\subsection{Pilot Test}

Before the actual experiment, a pilot session was conducted in order to test the procedure, the experiment design, the prototype, the position of the paintings on the shared tiled display and the displays setting. Several technical problems were found and solved during the pilot test. We only name a relevant one here:

Namely, the 'Highlight one image - fade the rest' checkbox (Figure 5, right bottom) was removed due to the distraction caused by the flashing effect on the Plasma Touch Screen. Since the Highlighting prototype was running on a Windows platform via SAGE interface, it was not possible to solve the flashing and therefore it was decided to ask the participants about the usefulness of this feature during a post group discussion and in the post-task questionnaire instead. The sliding bar (Figure 5. bottom) was left visible on the Highlighting interface. A user could highlight or fade a selected painting (or any projected window on the Tiled Display) by moving the slider left or right via direct touch or using a mimio pen on a Plasma Touch Screen (Figure 4, left). The effect was immediately visible on the Tiled Display (Figure 4 right).

\subsection{Multidisplay Environment Setting}

The experiment took place in the E-BioLab multidisplay meeting environment (see Figure 41). In all conditions, images were displayed on the central Tiled Display (5x4 lcd-monitors, resolution 1600x1200, 38 Megapixels) in the middle of the lab (Figure 4 , right image).

In condition N (No Highlighting interface), only a moving feature (via direct touch or using a mimio pen on a 63 -inch Plasma Touch Screen with a resolution of $1360 x 768$, Figure 4 left) of the interface was shown to the participants. That 

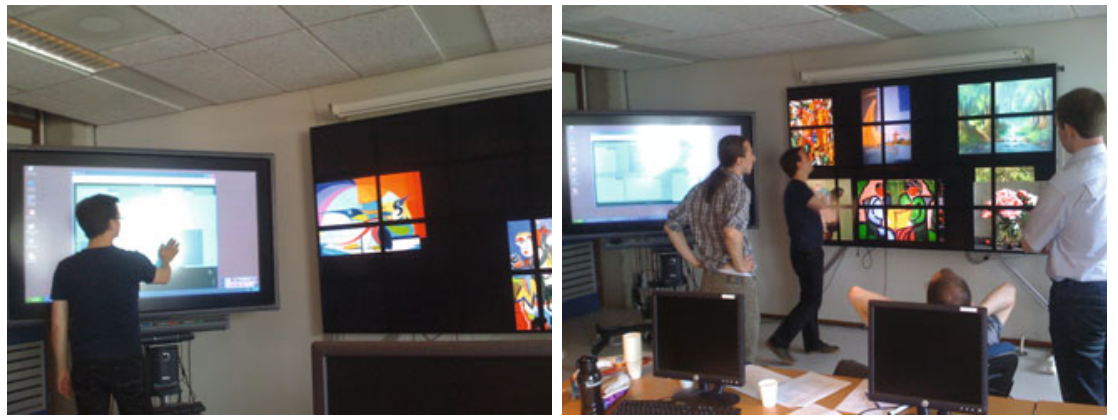

Fig. 4. Group session, Highlighting-On-Demand Experiment: group member interacting with the Highlighting interface on a plasma touch screen (left); group members discussing paintings displayed on the shared tiled display (right).

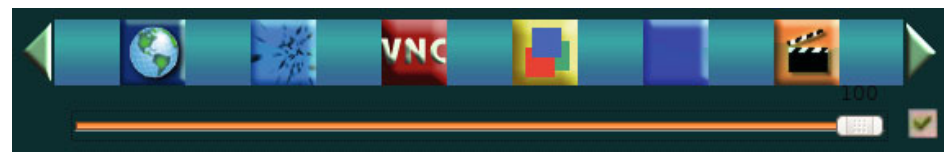

Fig. 5. Highlighting-On-Demand pilot

means that group members were only able to move and rearrange images on the Tiled Display (Figure 4, right), using the Highlighting-on-Demand interface version without a sliding bar below (Figure 6).

In condition $\mathrm{Y}$ (Highlighting interface), in addition to a moving feature as in $\mathrm{N}$ condition, participants were able to highlight or fade paintings (via direct touch or using a mimio pen on a Plasma Touch Screen, Figure 4 left). Interaction with the Highlighting interface was logged in a text file with time stamps. All sessions were captured with four video cameras from four different angles.
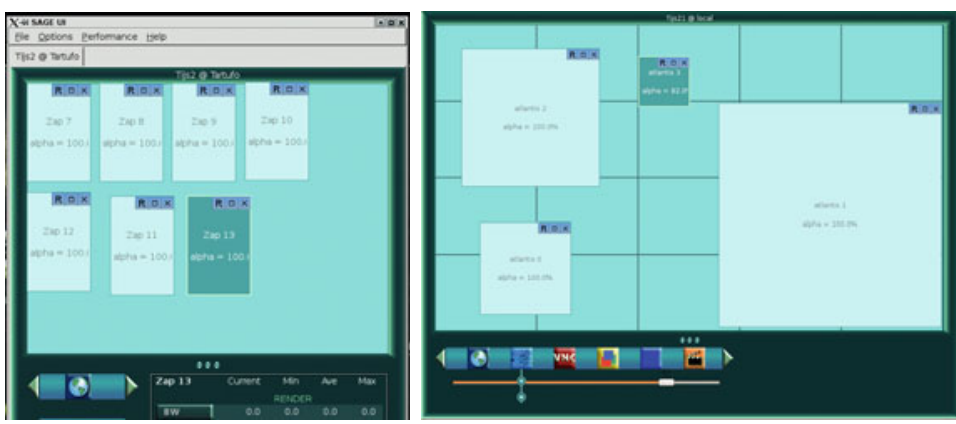

Fig. 6. Highlighting-On-Demand prototype: desktop version (left), image courtesy of Tijs de Kler, SARA; a touch screen version (right). 


\subsection{Measures}

Two dependent variables were measured: group process and decision making, and satisfaction. By keeping the team composition balanced and the task case constant in all groups, the effect of this variable was diminished. Likert scale questionnaires were applied to access the perceived group process quality Olaniran, 1996], satisfaction with the decision-making process Kulvk et al., 2006; Paul et al., 2004], and the perceived agreement with the final group decision. All questionnaires used 5-point Likert-scale, where ' 1 ' meant 'Strongly agree' and '5' - 'Strongly disagree'. Group process and decision making questionnaire was administered to team members in both $\mathrm{N}$ and $\mathrm{Y}$ condition.

Direct self-rating techniques, such as SART [Tavlon, 1989], have a potential limitation that participants may experience difficulties rating low periods of SA [Salmon et al., 2006]. In view of the rather short duration of the study, we predict that SART measure might not be sensitive enough for our case. Instead, we use perceived agreement with the final group decision as an indirect measure of shared situational awareness [Bolstad and Endslev, 2000; Wickens, 1992].

An additional set of questions addresses participants' subjective judgments about satisfaction with and usefulness of the Highlighting-on-Demand interface (including distraction and awareness) Cadiz et al., 2002; Kulvk et al., 2006; Paul et al., 2004]. Post-task usefulness questionnaire was administered to team members only in $\mathrm{Y}$ condition. The overview of all measurements and techniques is given below.

- Questionnaires:

1. Satisfaction with group process and decision making (Part I)

2. Perceived agreement (Part I)

3. Usefulness and satisfaction with the Highlighting-on-Demand interface; awareness and distraction (Part II)

- Observations (observation protocol)

- Post-session group interviews

- Video capturing (4 cameras)

\section{Data Analysis and Results}

The experiment results indicate that the use of the Highlighting interface on the shared display positively influenced team members' satisfaction with the final group decision. The main findings from the data analysis are discussed below.

\subsection{Participants}

In total 18 participants (15 male and 3 female, age range $25-31$ years) were recruited from the university community and assigned in 4 groups (2 groups of 5 members each, and 2 groups of 4 members each). Gender was split so that 3 groups out of 4 had members of both genders. Participants were mostly students, scientific programmers and postdoc researchers from three different 
research groups at the same university (University of Amsterdam, UvA) and had various scientific backgrounds (e.g., computer science, physics, computational biology, mathematics, engineering). None of the participants had experience with group discussion in the multidisplay environment before.

\subsection{Questionnaires}

\section{Group Process, Decision Making and Situational Awareness}

Wilcoxon Signed Ranks test was conducted to compare group members' satisfaction with the decision-making process in Y (Highlighting - condition 2) and N (No Highlighting - condition 1) conditions. There was a significant difference in the scores on the satisfaction with the final group decision, in relation to the personal preference, for the Y-Highlighting $\left(\mathrm{M}^{1}=4.67, \mathrm{SD}^{2}=0.48\right)$ and $\mathrm{N}-\mathrm{No}$ Highlighting $(\mathrm{M}=4.11, \mathrm{SD}=0.83)$ conditions; $\mathrm{n}=0.02(4=-2.33)$. Table 3 shows the results of a Wilcoxon Signed Ranks test only for the significant result - satisfaction with the final group decision. There was no significant difference found in the scores on the satisfaction with the group process and the decision-making process (Wilcoxon Signed Ranks test).

Table 3. Wilcoxon signed ranks test for the differences between N (No Highlighting) and Y (Highlighting) condition

\begin{tabular}{l||l|l|l}
\hline Questions: Decision Making Process & $\begin{array}{l}\text { N: Mean } \\
\text { (SD) }\end{array}$ & $\begin{array}{l}\text { Y: Mean } \\
\text { (SD) }\end{array}$ & Sig. \\
\hline \hline $\begin{array}{l}\text { Overall, I am satisfied with the final decision of } \\
\text { the group, in relation to my personal preference. }\end{array}$ & $4.11(0.83)$ & $4.67(0.48)$ & 0.02 \\
\hline
\end{tabular}

These results suggest that the Highlighting-on-Demand interface really does have an effect on the satisfaction with the final group decision. Specifically, our results suggest that when group members use the highlighting interface during the discussion, the satisfaction with the final group decision increases. In this manner, H2, stating that participants' satisfaction about the final group decision, in relation to their individual decision, will be higher in the condition with the Highlighting interface, is confirmed. On the other hand, H1, stating that in the condition with the Highlighting-on-Demand interface participants satisfaction about the group process, and the decision-making process will be higher, is not confirmed.

Perceived agreement with the final group decision is an implicit measure of shared situational awareness Bolstad and Endslev, 2000; Fiermestad, 2004;

\footnotetext{
1 M - Mean

${ }^{2} \mathrm{SD}$ - Standard Deviation

${ }^{3} \mathrm{p}$ - probability value

$4 \mathrm{z}$ - critical value for a $95 \%$ confidence interval (or a $5 \%$ level of significance); a shortcut to the hypothesis testing of the Wilcoxon signed rank-test.
} 
Wickens, 1992]. This suggests that in the condition with the Highlighting-onDemand support, the situational awareness was higher in terms of the perceived quality of group decisions and level of consensus. As the study of Wickens 1992] also indicates the ability of group members to accurately perform probabilistic diagnosis (situational awareness) coupled with the assigned values of different alternatives (ranking game), results in more satisfactory group decisions.

\section{Usefulness, Awareness and Distraction}

We balanced the valence of our satisfaction questions. For negatively phrased questions (marked with an asterisk in Table 4 and Table [5), we reversed the rating so that higher was always positive. The rating for the ability to focus the attention of others on certain information on the large display was above the average but not high enough. One of the reasons could be the difficulty to self-report the allocation of attention of oneself and others. More objective measures like eye gaze might be more efficient in this case, though there is still no eye-gaze tracking system applicable for dynamic group settings. Counting the number of times a participant attends to a certain display or a part of the display is another option, though it is burdensome and requires at least one observer per participant.

Ratings on awareness and distraction were also mostly neutral to positive (see Table 51). Awareness and distraction ratings indicate that the Highlighting interface did not distract participants from group discussion, but did not make then more aware of the information on the large display.

Ratings on usefulness and satisfaction with the Highlighting interface were mostly neutral to positive (see Table 4). From the ratings, it is clear that participants had no difficulty understanding the Highlighting interface and did not need more training to understand the interface. Group members also stated that they had confidence in the information provided by the Highlighting interface.

Table 4. Questionnaire results: usefulness and satisfaction

\begin{tabular}{l||l|l}
\hline & Question & $\begin{array}{l}\text { Average } \\
\text { Rating } \\
\text { (SD) }\end{array}$ \\
\hline \hline $\mathbf{1 .}$ & I have difficulty understanding the highlighting interface. ${ }^{*}$ & $4.7(0.5)$ \\
\hline $\mathbf{2 .}$ & Highlighting interface is easy to use. & $3.3(1.4)$ \\
\hline $\mathbf{3 .}$ & Highlighting interface is reliable. & $3.0(1.4)$ \\
\hline $\mathbf{4 .}$ & $\begin{array}{l}\text { I have confidence in the information provided by the highlighting } \\
\text { interface. }\end{array}$ & $4.0(0.9)$ \\
\hline $\mathbf{5 .}$ & I need more training to understand the highlighting interface. ${ }^{*}$ & $4.8(0.4)$ \\
\hline $\mathbf{6 .}$ & $\begin{array}{l}\text { I find the information provided by the highlighting interface infor- } \\
\text { mative. }\end{array}$ & $3.3(0.8)$ \\
\hline $\mathbf{7 .}$ & $\begin{array}{l}\text { The information provided by the highlighting interface is compre- } \\
\text { hensible. }\end{array}$ & $3.6(0.8)$ \\
\hline $\mathbf{8 .}$ & Overall, I am satisfied with the highlighting interface. & $3.1(1.1)$ \\
\hline $\mathbf{9 .}$ & I would be happy to use the highlighting interface in the future. & $3.3(1.3)$ \\
\hline
\end{tabular}


Table 5. Questionnaire results: awareness and distraction

\begin{tabular}{l||l|l}
\hline & Question & $\begin{array}{l}\text { Average } \\
\text { Rating } \\
\text { (SD) }\end{array}$ \\
\hline \hline $\mathbf{1 .}$ & I found the highlighting interface distracting. & \\
\hline $\mathbf{2 .}$ & Highlighting interface helped to grab my attention at the right time. & $3.0(1.2)$ \\
\hline $\mathbf{3 .}$ & Highlighting interface interrupted me during the group discussion. & $4.1(0.9)$ \\
\hline $\mathbf{4 .}$ & $\begin{array}{l}\text { Highlighting interface helped me to be aware of information on the } \\
\text { large display. }\end{array}$ & $3.0(1.3)$ \\
\hline $\mathbf{5 .}$ & $\begin{array}{l}\text { Highlighting interface helped me to focus the attention of others on } \\
\text { certain information on the large display. }\end{array}$ & $3.3(1.2)$ \\
\hline $\mathbf{6 .}$ & $\begin{array}{l}\text { I would rather have the highlighting interface displayed only pri- } \\
\text { vately.* }\end{array}$ & $2.1(1.0)$ \\
\hline
\end{tabular}

\section{User Preferences on the Highlighting Interface Features}

Three additional questions in the post-task questionnaire addressed the user preferences of the various features of the Highlighting interface, as well as the interaction preferences. The results indicate that 12 out of 18 participants found highlighting an image the most useful feature. Participants mentioned that the highlighting was helpful when eliminating choices: "...so that we could quickly/ efficiently move on to a decision. Visually removing eliminated options aided my group focus on the remaining choices". It was also used to emphasize, select an image, and to fade away the painting that didn't pass the vote. Among other mentioned useful features were: fading an image (7 of 18) and moving an image (4 out of 18).

Concerning the interaction preferences, 11 out of 18 participants preferred to interact with the highlighting interface via the touch screen. Tablet PC or a private PC screen was preferred by 6 out of 18 group members. Among other mentioned preferred means of interactions were, the direct manipulation on a tiled display (2 out of 18), interaction via speech (2 out of 18) and multitouch (2 out of 18$)$.

\section{User Comments}

Most participants had very positive responses about the highlighting interface:

- "I liked the intuitive interaction, you can directly manipulate things and everyone can see the changes right away";

- "Intuitive and fast. Would use it for spatial positioning";

- "I would like to use this for visualising data and manipulating how the data is visualised and discuss the data with others".

This first comment points to the ongoing awareness of changes in the environment. Several group members also mentioned that a feature to highlight one image and fade the rest would be useful. The wish-list features for the future highlighting interface is the multi-user and multitouch gesture interaction on the 
large display. Some participants complained about the black lines on the tiled display (2 out of 18), and about the reaction time of the touch display when resizing an image (1 out of 18).

Next, we discuss the qualitative results of the observations and the postsession discussions with the teams.

\subsection{The Use of Large Shared Display}

At the beginning of the discussion, group members would discuss each painting, why it would or would not be good to put it in the shared coffee room.

\section{N condition: No Highlighting Interface}

In $\mathrm{N}$ condition, participants used the Plasma Touch screen less intensively. If the whole group would eliminate a certain painting, a group would ask one member interacting with the plasma screen, to move that painting below or to the side of the Tiled display. In this way, participants were free to rearrange the screen as they wished, putting the most preferred paintings, or 'to be discussed' paintings in the middle or at the top of the tiled display.

\section{Y Condition: Highlighting Interface}

While going through each painting, in Y condition one of the participants would highlight or enlarg 5 the discussed painting. Spontaneous interactions also occurred frequently, when one group member would approach the plasma touch screen and would start interacting with the highlighting interface during the discussion, intuitively following the requests of the other team members as to which painting to highlight or to fade.

\section{N \& Y Conditions}

The results of our previous observations [Kulvk, 2010] and video analysis of scientific team discussions in the multidisplay e-BioLab environment showed that life scientists tend to walk to the shared tiled display to inspect a specific detail of a visualisation. This indicates that, unlike a static projection in the meeting room, a large shared display plays an important role in engaging the group members in the discussion. This points to the dynamic nature of interactions as reported in other studies [Tan et al., 2006]. Even though in this experiment only paintings were displayed and there was no need to inspect specific details of each painting during the group task, in both conditions participants still tended to gather around the display while discussing the alternatives and making the group decision. Participants tended to point at the shared large display when referring to one painting, also referring to it by a given name, such as a 'boy', or 'flowers' (Figure 2, paintings set B).

\footnotetext{
${ }^{5}$ Despite that only the Highlighting feature was encouraged to use in the Y condition, and moving in $\mathrm{N}$ condition, users also discovered the resizing feature during the test session as it was fairly intuitive. Even though resizing was not very easy, it was still used by some participants.
} 


\subsection{Interaction with the Highlighting-on-Demand interface}

The majority of participants liked interacting with the Highlighting interface via the shared Plasma Touch Screen as it helped the other group members to follow what was being changed on the shared large screen during the discussion. Some participants also mentioned that they would also like to interact with the Highlighting interface on a private Tablet PC.

Next to using the Highlighting-on-Demand in Y condition, and moving feature in $\mathrm{N}$ condition, users also discovered the resizing feature during the test session as it was fairly intuitive. One of the shortcomings of the particular touch screen used in this study was the response delay when resizing an image, also caused by the fact that the SAGE user interface was originally designed for the Tablet PC. Precision was hard to achieve when resizing an image by hand on a Plasma Touch Screen. Even though resizing was not very easy, it was still used by some participants. Therefore resizing might have effected the results. Since a resizing feature was a standard SAGE interface option, and in this experiment we focus only on the Highlighting interface, we did not focus on the redesign of the SAGE interface.

Several participants who were previously very familiar with touch screens, missed the multitouch feature on the Plasma Touch Screen. On the other hand, though the Plasma Touch Screen allowed only one person to interact at a time, it helped other group members to constantly stay aware of who was in control of the shared large display during the discussion. We did not observe any conflicts between group members concerning the interaction with the Plasma Touch Screen.

\subsection{Individual and Group Decision Making Strategies}

Most groups used the individual ranking approach to come up with the group decision, by summing up the individual ranks after they had made their personal choice. One of the group members would usually use a whiteboard to write down the ranks, or alternatively one by one each group member would write his/her personal rank on the whiteboard.

Some of the groups tended to discuss the strategy of the individual ranking for longer than 10 minutes. For instance, one very active participant in the fourth group changed the personal ranking of paintings in order to influence the final group decision in his favour.

\section{Reflections and Future Work}

The results of the observations and post-session group discussions indicate a high involvement of group members in the discussion while interacting with the highlighting interface on the shared display. This effect could be partially caused by the novelty of touch displays. 
One of the shortcomings of the study is that it was hard for the participants to make a clear distinction between the Highlighting interface and the rest of the touch screen's features such as moving and resizing. Some of the participants even mentioned that, if they had not been being told clearly, they would refer to all interfaces and displays in the environment while filling in the usefulness questionnaire on the usefulness of the Highlighting interface.

Previous studies by van Nimwegen et al. 2006] and O'Hara and Pavne 1999. discuss a counterproductive effect of the interfaces that present information externally on the display and fade out irrelevant information. On one hand, when information is externalized on the display (for example, by graying out momentarily unavailable buttons), users might quickly perform a problem solving task in a short run. On the other hand, the strong reliance on a visual display may have negative consequences for knowledge acquisition and task performance in the long run. We believe that giving users control over what parts of the information should or should not be externalized might be an alternative solution to the automatic information externalization. Although we did not study the longterm learning effects on the perceived performance (satisfaction with the final group decision), the results of our study suggest that providing the Highlightingon-Demand support might help to prevent the counterproductive effects named above on the group performance in problem solving tasks.

As for the role of a large display compared to just having paintings printed as large posters on the wall, we believe that interaction played an important role in our experiment. Besides the presence of a shared visual representation and the awareness of the fact that the team members can refer to the same visual representation, being able to perform simple interaction like fading, resizing and hiding the painting played a certain role in the group decision-making strategy. One of the other points on our research agenda is to study the long-term effects of shared large displays on situational awareness and decision-making strategies between co-located and distributed groups.

\section{Summary}

This chapter presented the results of the first empirical user study on the effect of the Highlighting-on-Demand concept on satisfaction with the group decision-making outcome in a real multidisplay environment. The Highlightingon-Demand interface enables a team member who is currently controlling the shared display to draw the attention of the other team members by highlighting a certain visualisation by using a slider on a touch display. The results suggest that when group members use the Highlighting-on-Demand interface during the discussion, the satisfaction with the final group decision increases. Participants expressed willingness to use the Highlighting awareness support for visualising data and manipulating how the data is visualised to discuss the data with other team members in real project discussions. 


\section{References}

Bolstad, C., Cuevas, H., Gonzalez, C., Schneider, M.: Modeling shared situation awareness. In: Proceedings of the 14th Conference on Behavior Representation in Modeling and Simulation (BRIMS 2005), Los Angles, CA, USA (2005)

Bolstad, C.A., Endsley, M.R.: The effect of task load and shared displays on team situation awareness. In: Proceedings of the 44th Annual Meeting of the Human Factors and Ergonomics Society, pp. 189-192. The Human Factors and Ergonomics Society, Santa Monica (2000)

Bray, R., Johnson, D., Chilstrom, J.: Social influence by group members with minority opinions: A comparison of hollander and moscovici. Journal of Personality and Social Psychology 43, 78-88 (1982)

Brown, R.: Group polarization. In: Brown, R. (ed.) Social Psychology, pp. 200-248. Free Press, New York (1986)

Cadiz, J.J., Venolia, G., Jancke, G., Gupta, A.: Designing and deploying an information awareness interface. In: Proceedings of the 2002 ACM Conference on Computer Supported Cooperative Work (CSCW 2002), pp. 314-323. ACM Press, New York (2002)

Crane, P.: Theories of expertise as models for understanding situation awareness. In: Proceedings of the 13th Annual Symposium on Psychology in the Department of Defense, pp. 148-152 (1992)

DiMicco, J., Pandolfo, A., Bender, W.: Influencing group participation with a shared display. In: Proceedings of the ACM conference on Computer Supported Cooperative Work (CSCW 2004), pp. 614-623. ACM Press, New York (2004)

Endsley, M.: A survey of situation awareness requirements in air-to-air combat fighters. International Journal of Aviation Psychology 3(2), 157-168 (1993)

Endsley, M.: Measurements of situation awareness in dynamic systems. Human Factors 37(1), 65-84 (1995a)

Endsley, M.: Toward a theory of situation awareness in dynamic systems. Human Factors Special Issue: Situation Awareness 37(1), 32-64 (1995b)

Fjermestad, J.: An analysis of communication mode in group support systems research. Decision Support Systems 37(2), 239-263 (2004)

Fruchter, R., Cavallin, E.: Developing methods to understand discourse and workspace in distributed computer-mediated interaction. AI and Society 20(2), 169-188 (2006)

Hackman, J.R.: Group influences on individuals in organizations. In: Dunnette, M.D., Hough, L.M. (eds.) Handbook of Industrial and Organizational Psychology, vol. 3, Consulting Psychologists Press, Palo Alto (1992)

Hallnass, L., Redstrom, J.: From use to presence: On the expressions and aesthetics of everyday computational things. ACM Transactions on Computer-Humon Interaction 9(2), 106-124 (2002)

Janis, I.: Groupthink: Psychological studies of policy decisions and fiascos. Houghton Mifflin, Boston (1982)

Kulyk, O.: Do You Know What I Know? Situational Awareness of Co-located Teams in Multidisplay Environments. PhD thesis, University of Twente (2010)

Kulyk, O., van Dijk, E., van der Vet, P., Nijholt, A.: Do you know what i know? situational awareness and scientific teamwork in collaborative environments. In: Nijholt, A., Stock, O., Nishida, T. (eds.) Proceedings Sixth Workshop on Social Intelligence Design (SID 2007). CTIT Workshop Proceedings Series, vol. WP07-02, pp. 207-215. Centre for Telematics and Information Technology, University of Twente, Enschede, The Netherlands (2007) 
Kulyk, O., van der Veer, G., van Dijk, E.: Situational awareness support to enhance teamwork in collaborative environments. In: Proceedings of the 15th European Conference on Cognitive Ergonomics (ECCE 2008), pp. 18-22. ACM Press, New York (2008)

Kulyk, O., Wang, J., Terken, J.: Real-time feedback on nonverbal behaviour to enhance social dynamics in small group meetings. In: Renals, S., Bengio, S. (eds.) MLMI 2005. LNCS, vol. 3869, pp. 150-161. Springer, Heidelberg (2006)

McGrath, J.E.: Groups: Interaction and Performance. Prentice Hall College Div., Englewood Cliffs (1984)

McGrath, J.E., Hollingshead, A.B.: Groups Interacting with Technology: Ideas, Evidence, Issues and an Agenda. Sage Publications, Inc., Thousand Oaks (1993)

Myers, D., Bishop, G.: The enhancement of dominant attitudes in group discussion. Journal of Personality and Social Psychology 20, 385-391 (1971)

van Nimwegen, C.C., Burgos, D.D., van Oostendorp, H.H., Schijf, H.H.J.M.: The paradox of the assisted user: guidance can be counterproductive. In: Proceedings of the SIGCHI Conference on Human Factors in Computing Systems (CHI 2006), pp. 917926. ACM Press, New York (2006)

O'Hara, K.P., Payne, S.J.: Planning and the user interface: the effects of lockout time and error recovery cost. International Journal of Human-Computer Studies 50(1), 41-59 (1999)

Olaniran, B.A.: A model of group satisfaction in computer-mediated communication and face-to-face meetings. Behaviour and Information Technology 15(1), 24-36 (1996)

Paul, S., Seetharaman, P., Ramamurthy, K.: User satisfaction with system, decision process, and outcome in gdss based meeting: An experimental investigation. In: Proceedings of the 37th Hawaii International Conference on System Sciences (HICSS 2004). IEEE Computer Society Press, Los Alamitos (2004)

Raven, B.: Groupthink, bay of pigs, and watergate reconsidered. Organizational Behavior and Human Decision Processes 73(2/3), 352-361 (1998)

Salmon, P., Stanton, N., Walker, G., Green, D.: Situation awareness measurement: A review of applicability for c4i environments. Applied Ergonomics 37(2), 225-238 (2006)

Stasser, G., Titus, W.: Effects of information load and percentage of shared information on the dissemination of unshared information during group discussion. Journal of Personality and Social Psychology 53, 81-93 (1987)

Tan, D., Gergle, D., Scupelli, P., Pausch, R.: Physically large displays improve performance on spatial tasks. ACM Transactions on Computer-Human Interaction 13(1), 71-99 (2006)

Taylor, R.M.: Situational awareness rating technique (sart): The development of a tool for aircrew system design. In: Proceedings of the Symposium on Situational Awareness in Aerospace Operations, AGARD-CP-478 (1989)

Whittaker, S.: Things to talk about when talking about things. Human-Computer Interaction 18(1), 149-170 (2003)

Whyte, G.: Decision failures: Why they occur and how to prevent them. Academy of Management Executive 5, 23-31 (1991)

Wickens, C.: Workload and situation awareness: An analogy of history and implications. In: Insight: The Visual Performance Technical Group Newsletter, pp. 1-3 (1992) 